\title{
Blood pressure percentiles and systemic hypertension-associated factors among children aged between 6 and 15 years in Southern Vietnam
}

\author{
Lam Van Nguyen', Phuoc Ngoc Truong', Le Thi Nhu Tran', Nghia Quang Bui', Khanh Truong Lieu², \\ Gai Thi Le', Tram Thi Thu Nguyen' \\ 'Can Tho University of Medicine and Pharmacy, Can Tho, Vietnam \\ ${ }^{2}$ Can Tho Central General Hospital, Can Tho, Vietnam
}

\begin{abstract}
Background: The present study determined blood pressure percentiles in children aged between 6 and 15 years in Southern Vietnam.

Material and methods: Blood pressure was measured in a random sample of 1080 students aged 6-15 years who was studying at primary and secondary high schools in My Tho city, Vietnam. A descriptive cross-sectional study was conducted from November 2019 to June 2020. To diagnose children systemic hypertension, the blood pressure must be above the $95^{\text {th }}$ percentile. Data were analyzed by IBM SPSS statistics software version 20.0. The Chi-squared test was employed to evaluate the relationship between systemic hypertension and child demographic characteristics including gender and obesity.

Results: The results showed that the 95th percentiles of systolic and diastolic blood pressure of the children was $110 / 70 \mathrm{~mm} \mathrm{Hg}$ in the 6-year-old group, $120 / 75 \mathrm{~mm} \mathrm{Hg}$ in the 7 to 12-year-old group and $125 / 80 \mathrm{~mm} \mathrm{Hg}$ in the 13 to 15 -year-old group, respectively. The rate of systemic hypertension in the children was $10 \%$ whereas boys had a 1.2 time higher risk of systemic hypertension than girls $(\mathrm{p}>0.05)$. Obese children had an 8.6 time higher risk of systemic hypertension than non-obese ones $(\mathrm{p}<0.001)$.

Conclusion: The blood pressure percentile chart of school children aged 6-15 years were reported here for the first time in Vietnam. The results provided useful information in early diagnosis and timely treatment of systemic hypertension in children.
\end{abstract}

Key words: blood pressure; children; hypertension; percentile chart

$$
\text { Arterial Hypertens. 2021, vol. 25, no. 2, pages: 77-81 }
$$

DOI: 10.5603/AH.a2021.0011

\section{Introduction}

Systemic hypertension is associated with long-term negative health effects not only in adults, but also in children and adolescents. It has been recognized as a major cause for cardiovascular morbidity and mortality [1]. Normally, high blood pressure in children was often neglected in diagnostic process. In

Address for correspondence: Tram Thi Thu Nguyen, Faculty of Sciences, Can Tho University of Medicine and Pharmacy, 179 Nguyen Van Cu, Can Tho 94000, Vietnam, tel: (+84) 919886682, e-mail: ntttram@ctump.edu.vn

This article is available in open access under Creative Common Attribution-Non-Commercial-No Derivatives 4.0 International (CC BY-NC-ND 4.0) license, allowing to download articles and share them with others as long as they credit the authors and the publisher, but without permission to change them in any way or use them commercially 
a study from 1999 to 2006 of 14187 children and adolescents aged 3 to 18 years in Cleveland, the United States, 507 of the children (3.6\%) had systemic hypertension but only a quarter was diagnosed [2]. The lack of information on pediatric hypertension had a direct detrimental effect on diagnosis and treatment $[3,4]$. In fact, the standard blood pressure tables were essential to provide recommendations for diagnosis, evaluation, and treatment of systemic hypertension [5]. Several worldwide studies were performed to establish blood pressure reference values. The National Health and Nutrition Examination Survey 1999-2000 (NHANES) presented blood pressure tables including the $50^{\text {th }}, 90^{\text {th }}, 95^{\text {th }}$, and $99^{\text {th }}$ percentiles by sex, age, and height [6]. Another study performed in India in $1999(\mathrm{n}=10215$ children) reported children aged 5-9 years had systolic blood pressure (SBP) ranging from 70 to 140 $\mathrm{mm} \mathrm{Hg}$, diastolic blood pressure (DBP) ranging from 36 to $100 \mathrm{~mm} \mathrm{Hg}$, while BP values in children aged $10-14$ years were $72-160 \mathrm{~mm} \mathrm{Hg}$ and $46-120$ $\mathrm{mm} \mathrm{Hg}$, respectively. The study also provided the rates of systemic hypertension which were $11.9 \%$ for boys and $11.4 \%$ for girls [7]. However, Vietnam has not reported a typical blood pressure table for children yet. So far, the blood pressure tables for foreign children have been used in diagnosis and treatment of systemic hypertension for children in Vietnam, which often led to some errors due to a great difference in characteristics between Vietnamese and foreign children. Moreover, the Vietnam National Association of Cardiology has not showed the status of systemic hypertension in children yet. The present study determined blood pressure percentiles of children aged 6-15 years old in southern Vietnam, which contributed to improved treatment for underage patients in this country.

\section{Material and methods}

\section{Study population}

A descriptive cross-sectional study was conducted from November 2019 to June 2020. The study was performed at 6 schools in My Tho city, southern Vietnam. My Tho has a population of 165,074 in which urban population accounts for $74.76 \%$. The Kinh, the most predominant ethnic group, accounts for $98 \%$ of its population, followed by the Hoa ethnic group $(1.89 \%)$ and the remaining ones are Khmer and Indian ethnic groups. Regarding education, My Tho has 19 primary schools with 393 classes and 13,880 students, on average 30-35 students/class. There were also 7 secondary high schools with 229 classes and 9,911 students, on average 40-45 students/class. Overall, twenty-six schools are located in 10 wards belonging to 4 communities. In terms of healthcare, there has not been any published study on systemic hypertension in children as well as in adults. In this study, 1,080 children of 10 age groups (the average age was $10.5 \pm 2.87$ ), from grade 1 to grade 9, were enrolled. Each grade had 108 participants, except 9th grade with 216 children divided equally into two groups of ages (ages 14-15). Each age group average accounts for $10 \%$ of the total number of children enrolled in the study.

\section{Method of blood pressure measurement}

Blood pressure in children was measured according to four steps as described below:

- step 1: chose randomly 3 primary schools and 3 secondary high schools from 26 schools;

- step 2: select all grade classes from the six randomly chosen schools;

- step 3: at each grade in any school, select randomly 36 children meeting eligibility criteria;

- step 4: collect statistics of all children who meet the following selection criteria.

Inclusion criteria in the study were as follows: $1-6-15$-year-old male and female students living and studying at primary and secondary schools in My Tho city during the study period; 2 - subjects and families accepted to participate in the study. The blood pressure evaluation included sphygmomanometer technique (seated, measure blood pressure 3 times) measurement of systolic (SBP) and diastolic blood pressure (DBP) [8]. Blood pressure values were obtained with certified mercury sphygmomanometers by trained examiners following the standard protocol recommended by the AHA. In brief, after at least 5 minutes of rest, blood pressure was obtained on the right arm of the seated children with the elbow at the level of the right atrium, using an appropriately sized cuff. The feet of children were on a platform during blood pressure measurement. Systolic blood pressure was determined by the onset of the first Korotkoff sound (i.e., appearance of tones) and DBP was determined by the fifth Korotkoff sound (i.e., total disappearance of tones). Blood pressure was measured up to three times on one occasion, with intervals of several minutes [9]. Anthropometric measurements included body weight and height.

Exclusion criteria in the study were as follows: 1 - children with hand deformities whose blood pressure cannot be measured; 2 - children who drank coffee $1 \mathrm{~h}$ before the measurement; 3 - children who ate, drank, used alcohol or any other stimulant 
Table 1. Distribution of systolic (SBP) and diastolic (DBP) blood pressure by age

\begin{tabular}{|c|c|c|c|c|c|c|c|c|}
\hline \multirow[b]{2}{*}{$\begin{array}{l}\text { Years } \\
\text { of age }\end{array}$} & \multicolumn{4}{|c|}{ SBP } & \multicolumn{4}{|c|}{ DBP } \\
\hline & $\begin{array}{c}\text { Median blood } \\
\text { pressure } \\
{[\mathrm{mm} \mathrm{Hg}]}\end{array}$ & $\begin{array}{l}\text { Standard } \\
\text { deviation } \\
{[\mathrm{mm} \mathrm{Hg}]}\end{array}$ & $\begin{array}{c}\text { Min } \\
{[\mathrm{mm} \mathrm{Hg}]}\end{array}$ & $\begin{array}{c}\text { Max } \\
{[\mathrm{mm} \mathrm{Hg}]}\end{array}$ & $\begin{array}{l}\text { Median blood } \\
\text { pressure } \\
\text { [mm Hg] }\end{array}$ & $\begin{array}{l}\text { Standard } \\
\text { deviation } \\
{[\mathrm{mm} \mathrm{Hg}]}\end{array}$ & $\begin{array}{c}\text { Min } \\
{[\mathrm{mm} \mathrm{Hg}]}\end{array}$ & $\begin{array}{c}\text { Max } \\
{[\mathrm{mm} \mathrm{Hg}]}\end{array}$ \\
\hline 6 & 93 & 9.03 & 80 & 120 & 55 & 7.69 & 38 & 70 \\
\hline 7 & 99 & 9.58 & 80 & 130 & 60 & 7.55 & 45 & 80 \\
\hline 8 & 99 & 9.12 & 80 & 120 & 62 & 7.58 & 43 & 80 \\
\hline 9 & 101 & 9.27 & 80 & 130 & 63 & 7.27 & 45 & 80 \\
\hline 10 & 99 & 9.71 & 78 & 130 & 62 & 7.22 & 48 & 80 \\
\hline 11 & 101 & 10.31 & 80 & 140 & 63 & 7.48 & 50 & 90 \\
\hline 12 & 103 & 12.78 & 80 & 142 & 63 & 8.53 & 50 & 100 \\
\hline 13 & 109 & 9.56 & 90 & 130 & 70 & 8.32 & 42 & 90 \\
\hline 14 & 106 & 10.63 & 80 & 130 & 67 & 7.34 & 50 & 80 \\
\hline 15 & 109 & 12.39 & 80 & 145 & 68 & 8.24 & 50 & 88 \\
\hline
\end{tabular}

30 min before the measurement; 4 - children used tobacco and medications that may affect the amount of blood pressure.

Overweight and obesity status was assessed based on age- and sex-specific BMI percentiles as recommended by the International Obesity Task Force [10].

\section{Data analysis}

Collecting research data was based on the use of survey questionnaires, blood pressure, height, and weight measurements on each patient. IBM SPSS version 20.0 software was used to process the collected data. The relationship between systemic hypertension and demographic characteristics (gender, obesity) of children was analyzed by $\chi^{2}$ test. To compare quantitative variables, independent sample t test and one-way ANOVA were used.

\section{Results}

\section{Study population}

In this study, 1080 children met the criteria of the study. The information of the children was as follows: male students accounted for $48.8 \%$ and female students accounted for $51.2 \%$; the average height of the children was $138.5 \pm 15.7$ centimeters (min 101, $\max 177.5$ ); the average weight of the children was $34.7 \pm 11.4$ kilograms (min 13.5, $\max 75)$; average BMI was $17.6 \pm 3.1(\min 10.5, \max 42.3)$; average SBP was $101.9 \pm 11.3 \mathrm{~mm} \mathrm{Hg}(\min 60, \max 145)$; average DBP was $63.2 \pm 8.8 \mathrm{~mm} \mathrm{Hg}(\min 38$, max 100). When the average SBP increased by $1 \mathrm{mmHg}$, the average DBP would increase by $0.6 \mathrm{~mm} \mathrm{Hg}$. SBP explained $59.6 \%$ of the variation of the average in the research sample $(\mathrm{DBP}=2.45+0.6 * \mathrm{SBP}$; $\mathrm{F}=1587.8, \mathrm{p}<0.001,95 \%$ confidence interval 35.61-41.88). The children's blood pressure index increased with age; the difference in SBP and DBP between ages was statistically significant $(p<0.001)$. However, when comparing each age group separately, the 6-year-old children had the lowest SBP and DBP, and children aged 7-12 years have lower SBP than children aged 13-15 years; all of these differences were statistically significant for each group $(\mathrm{p}<0.05)$. The difference in SBP and DBP between children aged 7-12 years and 13-15 years was not statistically significant $(\mathrm{p}>0.05)$ (Tab. 1$)$.

\section{Blood pressure percentiles of children}

The results showed that the 95th percentiles of SBP and DBP of children in the 6-year-old group were 110/70 mm Hg; these values were 120/75 mm Hg and $125 / 80 \mathrm{~mm} \mathrm{Hg}$ for the 7-12-year-old group and the 13-15-year-old group, respectively (Tab. 2).

\section{The rate of systemic hypertension in children}

The rate of systemic hypertension in children was $108(10 \%)$. This rate was concentrated mainly in children of secondary schools. The difference in the threshold rate and actually between ages was statistically significant $(\mathrm{p}<0.001)$. Secondary school students had a 2.6-time higher systemic hypertension rate than primary school ones $(\mathrm{p}<0.001)$ (Tab. 3).

\section{Risk factors for systemic hypertension in children}

Boys had a 1.2-time higher risk of systemic hypertension than girls, which was not statistically significant $(p>0.05)$. the difference between obese and non-obese children was also statistically signifi- 
Table 2. The $90^{\text {th }}$ and $95^{\text {th }}$ percentiles for blood pressure by age group

\begin{tabular}{|c|c|c|c|c|c|c|}
\hline Years of age & Number & $\begin{array}{c}\text { Blood pressure } \\
{[\mathrm{mm} \mathrm{Ha]}}\end{array}$ & \multicolumn{2}{|c|}{ Male } & \multicolumn{2}{|c|}{ Female } \\
\hline \multirow{3}{*}{6} & \multirow{3}{*}{108} & & $90^{\text {th }}$ & $95^{\text {th }}$ & $90^{\text {th }}$ & $95^{\text {th }}$ \\
\hline & & SBP & 107 & 112 & 104 & 108 \\
\hline & & $\mathrm{DBP}$ & 67 & 72 & 63 & 68 \\
\hline \multirow{2}{*}{$7-12$} & \multirow{2}{*}{648} & SBP & 112 & 122 & 109 & 117 \\
\hline & & DBP & 72 & 77 & 69 & 74 \\
\hline \multirow{2}{*}{ 13-15 } & \multirow{2}{*}{324} & SBP & 122 & 127 & 118 & 123 \\
\hline & & DBP & 81 & 80 & 80 & 79 \\
\hline
\end{tabular}

SBP — systolic blood pressure; DBP — diastolic blood pressure

Table 3. Comparison of systemic hypertension between secondary and primary school students

\begin{tabular}{|c|c|c|c|c|c|c|}
\hline & \multicolumn{2}{|c|}{ Systemic hypertension } & \multicolumn{2}{|c|}{ Normal blood pressure } & \multirow{2}{*}{$\begin{array}{c}\text { OR } \\
(95 \% \mathrm{Cl})\end{array}$} & \multirow{2}{*}{$\begin{array}{l}\chi^{2} \\
\mathbf{p}\end{array}$} \\
\hline & Number & $\%$ & Number & $\%$ & & \\
\hline Secondary school & 76 & 14.1 & 464 & 85.9 & 2.6 & 19.91 \\
\hline Primary school & 32 & 5.9 & 508 & 94.1 & $(1.69-4.00)$ & $p<0.001$ \\
\hline
\end{tabular}

$\mathrm{OR}$ — odds ratio; $\mathrm{Cl}$ — confidence interval

Table 4. The relationship between the prevalence of systemic hypertension and sex or obesity

\begin{tabular}{|c|c|c|c|c|c|c|c|}
\hline & & \multicolumn{2}{|c|}{ Systemic hypertension } & \multicolumn{2}{|c|}{ Normal blood pressure } & \multirow{2}{*}{$\begin{array}{c}\text { OR } \\
(95 \% \mathrm{Cl})\end{array}$} & \multirow{2}{*}{$\begin{array}{l}\chi^{2} \\
\mathbf{p}\end{array}$} \\
\hline & & Number & Percentage & Number & Percentage & & \\
\hline \multirow{2}{*}{ Sex } & Male & 20 & 3.8 & 507 & 96.2 & \multirow{2}{*}{$\begin{array}{c}1.2 \\
(0.65-2.44)\end{array}$} & \multirow{2}{*}{$\begin{array}{c}0.42 \\
0.515\end{array}$} \\
\hline & Female & 17 & 3.1 & 536 & 96.9 & & \\
\hline \multirow{2}{*}{ Obese } & Yes & 23 & 12.1 & 167 & 87.9 & \multirow{2}{*}{$\begin{array}{c}8.6 \\
(4.3-17.1)\end{array}$} & \multirow{2}{*}{$\begin{aligned} & 52.5 \\
< & 0.001\end{aligned}$} \\
\hline & No & 14 & 1.6 & 876 & 98.4 & & \\
\hline
\end{tabular}

$\mathrm{OR}$ - odds ratio; $\mathrm{Cl}$ — confidence interval

cant ( $\mathrm{p}<0.001)$; namely, the former group had an 8.6-time higher risk of systemic hypertension than the latter (Tab. 4).

\section{Discussion}

The SBP of boys was $2.6 \mathrm{~mm} \mathrm{Hg}$ higher than that of girls $(\mathrm{p}<0.001)$. According to the previous study conducted at 6 countries in Europe on 28,043 children, the SBP of boys was also higher $6 \mathrm{~mm} \mathrm{Hg}$ than that of girls $[6,11]$. The $90^{\text {th }}$ and $95^{\text {th }}$ percentiles for SBP and DBP in children aged 6-15 years in this study were lower than that of children and adolescents in seven countries: China, India, Iran, Korea, Poland, Tunisia, and USA [5]. The cause could be the differences in race, habitat and between Vietnamese children and foreign children. It confirmed the necessary to establish a blood pressure index for children in Vietnam which would be helpful for doctors in diagnostic and treatment [12]. Besides, the rate of systemic hypertension in children (10\%) in our study absolutely agreed with that in the study of Salvador Fonseca-Reyes et al. (10.4\%) [8]. When compared to Vietnamese adults with the prevalence of hypertension of $28.7 \%$, this rate was lower in Vietnamese children [13]. In fact, the prevalence of hypertension increased with age. We found that the prevalence of hypertension is rising and tends to develop at an increasingly younger age. Yet further research is still needed for improving overall care for children and adolescents with hypertension. The results also showed that the sex had not statistical significant effect on pediatric hypertension. This observation was also consistent with the study performed on children of 5-14 year of age in New Delhi, India [7]. Obesity was another risk factor for pediatric hypertension; the increase in systemic hypertension of obese children was also reported on several previous studies [14-17]. Despite some strengths of the present analysis, the limitation was also recorded. The study was only performed on one city located in the 
southern region and the sample size was small; the blood pressure measurements didn't fully covered the representative sample of the population of Vietnamese children. For further research, a larger survey should be carried out on the pediatric hypertension situation for whole country. This should include regular health check-ups on the children with systemic hypertension to find the cause of systemic hypertension and evaluation of the relationship between obesity and systemic hypertension in children for the purpose of recommendation and prevention.

\section{Conclusion}

The present study provided for the first time the blood pressure percentile chart of school children aged 6-15 years in Vietnam. The rate of systemic hypertension in children was $10 \%$. The relationship between systemic hypertension and demographic characteristics of children, such as gender and obesity, were also observed. Further studies are in progress.

\section{Acknowledgements}

The authors would like to thank the participants involved in this study and the Faculty of Medicine, Can Tho University of Medicine and Pharmacy, Vietnam.

\section{Conflict of interest}

No conflict of interest was declared regarding the present article.

\section{Funding}

The author(s) received no financial support for the research, authorship, and/or publication of this article.

\section{References}

1. Sogunuru GP, Mishra S. Asian management of hypertension: Current status, home blood pressure, and specific concerns in India. J Clin Hypertens (Greenwich). 2020; 22(3): 479-482, doi: $10.1111 /$ jch.13798, indexed in Pubmed: 31955516.

2. Hansen ML, Gunn PW, Kaelber DC. Underdiagnosis of hypertension in children and adolescents. JAMA. 2007; 298(8): 874-879, doi: 10.1001/jama.298.8.874, indexed in Pubmed: 17712071 .

3. Vuppala S, Turer CB. Clinical Decision Support for the Diagnosis and Management of Adult and Pediatric Hypertension. Curr Hypertens Rep. 2020; 22(9): 67, doi: 10.1007/s11906-02001083-9, indexed in Pubmed: 32852616.
4. Riley M, Dobson M, Sen A, et al. Recognizing elevated BP in children and adolescents: how are we doing? . J Fam Pract. 2013; 62(6): 294-299, indexed in Pubmed: 23828801.

5. Xi Bo, Zong X, Kelishadi R, et al. International Child Blood Pressure References Establishment Consortium. Establishing International Blood Pressure References Among Nonoverweight Children and Adolescents Aged 6 to 17 Years. Circulation. 2016; 133(4): 398-408, doi: 10.1161/CIRCULATIONAHA.115.017936, indexed in Pubmed: 26671979.

6. National High Blood Pressure Education Program Working Group on High Blood Pressure in Children and Adolescents. The Fourth Report on the Diagnosis, Evaluation, and Treatment of High Blood Pressure in Children and Adolescents. Pediatrics. 2004; 114(2): 555-576, indexed in Pubmed: 15286277.

7. Chadha SL, Vasan RS, Sarma PS, et al. Age- and height-specific reference limits of blood pressure of Indian children. Natl Med J India. 1999; 12(4): 150-156, indexed in Pubmed: 10573968.

8. Fonseca-Reyes S, Romero-Velarde E, Torres-Gudiño E, et al. Comparison of auscultatory and oscillometric BP measurements in children with obesity and their effect on the diagnosis of arterial hypertension. Arch Cardiol Mex. 2018; 88(1): 16-24, doi: 10.1016/j. acmx.2017.01.005, indexed in Pubmed: 28238543.

9. Perloff D, Grim C, Flack J, et al. Human blood pressure determination by sphygmomanometry. Circulation. 1993; $88(5$ Pt 1): 2460-2470, doi: 10.1161/01.cir.88.5.2460, indexed in Pubmed: 8222141.

10. Cole TJ, Bellizzi MC, Flegal KM, et al. Establishing a standard definition for child overweight and obesity worldwide: international survey. BMJ. 2000; 320(7244): 1240-1243, doi: 10.1136/ bmj.320.7244.1240, indexed in Pubmed: 10797032.

11. Falkner B, Daniels SR. Summary of the Fourth Report on the Diagnosis, Evaluation, and Treatment of High Blood Pressure in Children and Adolescents. Hypertension. 2004; 44(4): 387-388, doi: 10.1161/01.HYP.0000143545.54637.af, indexed in Pubmed: 15353515.

12. Kavey REW, Daniels SR, Lauer RM, et al. American Heart Association. American Heart Association guidelines for primary prevention of atherosclerotic cardiovascular disease beginning in childhood. Circulation. 2003; 107(11): 1562-1566, doi: 10.1161/01. cir.0000061521.15730.6e, indexed in Pubmed: 12654618.

13. Van Minh H, Viet NL, Sinh CT, et al. Blood pressure screening during the May Measurement Month 2017 programme in Vietnam-South-East Asia and Australasia. Eur Heart J Suppl. 2019; 21(Suppl D): D127-D129, doi: 10.1093/eurheartj/suz076, indexed in Pubmed: 31043900.

14. Bonito PDi, Licenziati MR, Baroni MG, et al. CARITALY Study on the behalf of the Childhood Obesity Study Group of the Italian Society of Pediatric Endocrinology and Diabetology. The American Academy of Pediatrics hypertension guidelines identify obese youth at high cardiovascular risk among individuals non-hypertensive by the European Society of Hypertension guidelines. Eur J Prev Cardiol. 2020; 27(1): 8-15, doi: 10.1177/2047487319868326, indexed in Pubmed: 31387383.

15. Mangalam K, Muneesh C, Akshay A, et al. Prevalence of Overweight and Obesity among School Going Adolescent in Patna. Medico-Legal Updat. 2021; 21(1): 446-450, doi: 10.37506/mlu. v21i1.2350, indexed in Pubmed: 28274012.

16. Leung LCK, Ng DK, Lau MW, et al. Twenty-four-hour ambulatory BP in snoring children with obstructive sleep apnea syndrome. Chest. 2006; 130(4): 1009-1017, doi: 10.1378/ chest.130.4.1009, indexed in Pubmed: 17035432.

17. Zhu W, Huang X, He J, et al. Arterial intima-media thickening and endothelial dysfunction in obese Chinese children. Eur J Pediatr. 2005; 164(6): 337-344, doi: 10.1007/s00431-0051642-y, indexed in Pubmed: 15750804. 